\title{
Article \\ Using Azadirachtin to Transform Spodoptera frugiperda from Pest to Natural Enemy
}

\author{
Sukun Lin ${ }^{1}$, Shengnan $\mathrm{Li}^{1}{ }^{1}$, Zhenghui Liu ${ }^{2} \mathbb{(}, \mathrm{Li}_{\text {Zhang }}{ }^{1}$, Hao Wu ${ }^{1}$, Dongmei Cheng ${ }^{3, *}$ and Zhixiang Zhang ${ }^{1, *(1)}$ \\ 1 Key Laboratory of Natural Pesticide and Chemical Biology of the Ministry of Education, South China \\ Agricultural University, Guangzhou 510642, China; 13210615585@stu.scau.edu.cn (S.L.); \\ wjyz@stu.scau.edu.cn (S.L.); zhangli0810@stu.scau.edu.cn (L.Z.); wuhao@stu.scau.edu.cn (H.W.) \\ 2 Guangdong Provincial Key Laboratory of Petrochemical Pollution Process and Control, \\ Guangdong University of Petrochemical Technology, Maoming 525000, China; lzhhok@126.com \\ 3 Department of Plant Protection, Zhongkai University of Agricultural and Engineering, \\ Guangzhou 510225, China \\ * Correspondence: zkcdm@zhku.edu.cn (D.C.); zdsys@scau.edu.cn (Z.Z.)
}

check for

updates

Citation: Lin, S.; Li, S.; Liu, Z.; Zhang, L.; Wu, H.; Cheng, D.; Zhang, Z. Using Azadirachtin to Transform Spodoptera frugiperda from Pest to

Natural Enemy. Toxins 2021, 13, 541. https://doi.org/10.3390/ toxins13080541

Received: 30 June 2021

Accepted: 29 July 2021

Published: 3 August 2021

Publisher's Note: MDPI stays neutral with regard to jurisdictional claims in published maps and institutional affiliations.

Copyright: (c) 2021 by the authors. Licensee MDPI, Basel, Switzerland. This article is an open access article distributed under the terms and conditions of the Creative Commons Attribution (CC BY) license (https:// creativecommons.org/licenses/by/ $4.0 /)$.
Abstract: Spodoptera frugiperda and Rhopalosiphum maidis, as main pests, seriously harm the safety of maize. At present, chemical pesticides are mainly used to control these pests. However, due to residue and resistance problems, more green, environmentally benign, simple preventive control technology is needed. In this study, we reported the reason for the antifeedant activity of azadirachtin on S. frugiperda and proposed that S. frugiperda treated with azadirachtin would turn from pest into natural enemy. S. frugiperda showed an obvious antifeeding phenomenon to maize leaf treated with various azadirachtin concentrations $(0.5 \sim 20 \mathrm{mg} / \mathrm{L})$. It was found that maize leaf treated with $1 \mathrm{mg} / \mathrm{L}$ of azadirachtin has a stimulating effect on the antenna and sensillum basiconicum of S. frugiperda, and azadirachtin can affect the feeding behavior of $S$. frugiperda. Additionally, after treating maize leaves or maize leaves $+R$. maidis with $1 \mathrm{mg} / \mathrm{L}$ of azadirachtin, the predatory behavior of $S$. frugiperda changed from a preference for eating maize leaves to $R$. maidis. Moreover, the molting of $R$. maidis can promote the change of this predatory behavior. Our results, for the first time, propose that the combined control technology of azadirachtin insecticide and biological control could turn S. frugiperda from pest into natural enemy, which can effectively eliminate $R$. maidis and protect maize. This combined control technology provides a new way for pest management and has good ecological, environmental, and economic benefits.

Keywords: azadirachtin; maize; Spodoptera frugiperda; Rhopalosiphum maidis; natural enemy; pest control

Key Contribution: This study proposes that the combined control technology of azadirachtin insecticide and biological control could turn Spodoptera frugiperda from pest into natural enemy. The combined control technology provides a new way for pest management and has good ecological, environmental, and economic benefits.

\section{Introduction}

Maize (Zea mays L.) is one of the three major food crops in the world, and it is also one of the most economically important crops in China [1]. Studies have suggested that the demand for maize will gradually increase with the rapid increase in China's population and consequent economic growth [2]. Therefore, it is very important to ensure maize food security [3]. As the main pests on maize, Spodoptera frugiperda and maize aphid (Rhopalosiphum maidis) have seriously harmed the safety of maize [4,5].

S. frugiperda (J. E. Smith, 1797) is a kind of polyphagous migratory pest, which can cause considerable economic losses to more than 80 different crops [6]. This pest originated in tropical and subtropical areas of North, Central, and South America and has been 
regarded as the main pest of maize and several other crops for decades [7]. S. frugiperda was confirmed in several Asian countries including India, Sri Lanka, Thailand, Yemen, Myanmar, and Bangladesh in 2018 [8]. In China, this species was first found in the southeast of Yunnan Province in January 2019 and rapidly spread to most other provinces, causing serious damage to crops such as maize [9]. In 2018, published pest distribution and climatic suitability models indicated that there are environmental requirements for the permanent survival and reproduction of S. frugiperda in warmer regions of Asia [10]. Additionally, the geographical distribution model showed that most areas of China may be suitable for the survival of this destructive pest [11]. Farmers in the invaded areas are unprepared for this destructive pest, resulting in heavy losses and a sharp increase in the use of pesticides [12]. It is reported that farmers often use highly dangerous or prohibited pesticides and usually do not have appropriate personal protective equipment [13]. In addition to the strong ability of $S$. frugiperda to rapidly develop resistance to insecticides, overdependence on insecticides has become a major problem and will increase potential environmental and health risks [14]. Moreover, the large-scale application of pesticides increases the production cost. Farmers usually choose low-input methods to control pests and rely on natural biological control to a certain extent [15]. As a result, overdependence on insecticides is not in line with the integrated pest management (IPM) approach and is unsustainable in the long run. Currently, chemical control is still the main strategy against S. frugiperda in China, although some biological control experiments using predators have been conducted in the laboratory [16]. However, in the long run, more biological control strategies should be adopted against $S$. frugiperda to increase the sustainability of IPM programs.

Maize aphid (R. maidis Fitch), as another major pest on maize, is known to attack more than 30 genera and most cereal crops of Poaceae and was originally a species in Asia but is now distributed in tropical, subtropical, and warm temperate regions of the world [17]. R. maidis is harmful to the growth of maize by sucking the sap of the maize leaf [18]. In addition, it can spread the virus disease of the maize dwarf leaf, affect the photosynthesis of maize, cause the parasitism of mold, and reduce the yield in different degrees [19]. At present, the control of this pest mainly depends on strengthening field management and insecticides [20]. The use of insecticides aggravates the use and residues of pesticides and the cost of production, which undoubtedly needs to be improved to increase the sustainability of IPM programs.

Aiming to solve these problems more sustainably, we studied the effects of azadirachtin on the predation behavior of $S$. frugiperda. People have gradually shifted from the dependence on acute lethal effects to sublethal effects of insecticidal compounds, which is more in line with the sustainability of IPM programs [21]. Azadirachtin as a biopesticide, has a variety of resistance effects on many insects [22]. Additionally, previous research has shown that azadirachtin has repellent and antifeedant effects on many kinds of insects [23]. Biopesticides are usually unique and complex and have different modes of action, which means that pests are less likely to develop resistance, and biopesticides are often safer than chemical ones to the environment [24]. Azadirachtin arguably stands out as the most widely used biopesticide and is widely used in pest control [25].

In this study, we found that azadirachtin had antifeedant and repellent activities on S. frugiperda. Thus, we studied the effects of azadirachtin on the predation behavior of $S$. frugiperda. If azadirachtin treatment could change the predation behavior of the $S$. frugiperda, causing them to switch from eating maize leaf to preying on $R$. maidis, then it may be effective in killing $R$. maidis, significantly reducing the use of pesticides and protecting maize. Our study, for the first time, demonstrated that this combined control technology of azadirachtin insecticide and biological control could be considered as a new way for green, environmental protection and light control technology, with good ecological, environmental, and economic benefits. 


\section{Results}

\subsection{Toxicity of Azadirachtin to S. frugiperda}

The results of the indoor toxicity of azadirachtin to S. frugiperda are shown in Figure 1. It can be seen that after feeding maize leaves treated with different concentrations of azadirachtin $(0.5 \sim 20 \mathrm{mg} / \mathrm{L})$ for 3 days, the mortality rates varied significantly with respective concentrations. A mortality rate of $51.67 \%$ was evident when the larvae were fed with maize leaves treated with azadirachtin at $20 \mathrm{mg} / \mathrm{L}$; the mortality rates gradually declined with the concentration decrease and became only $11.67 \%$ at the concentration of $1 \mathrm{mg} / \mathrm{L}$. On the contrary, the mortality rate of the $S$ frugiperda fed with maize leaves without azadirachtin only was $8.33 \%$. In addition, it was found that the undead larvae of S. frugiperda in the treatment groups appeared to be slow, repelled from treated leaves and refusing to feed on maize leaves containing azadirachtin. Additionally, it is difficult for azadirachtin to cause the death of $S$. frugiperda within two days.

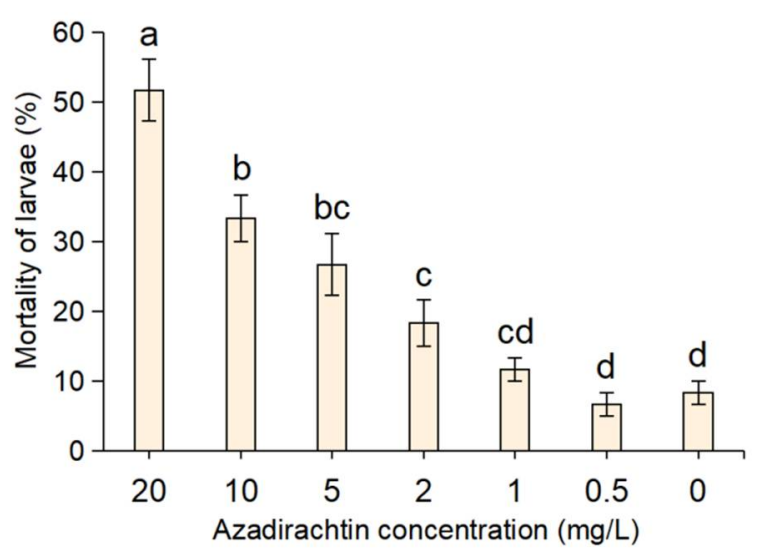

Figure 1. Mortality rates of $S$. frugiperda after three days of feeding with maize leaves treating different concentrations of azadirachtin. The ' 0 ' on the $x$-axis was the control, which means maize leaves without azadirachtin. Data are presented as mean \pm standard error (S.E.). Different letters above bars indicate significant differences in mortality among treatments due to concentration effects at $p<0.05$ level based on Tukey's honestly significant difference (HSD) test $(n=3)$.

\subsection{Effects of Azadirachtin on the Antenna and Sensilla of S. frugiperda}

A sublethal concentration of azadirachtin $(1 \mathrm{mg} / \mathrm{L})$ in maize leaves was selected for testing sublethal effects on S. frugiperda. Based on the avoidance and antifeeding phenomena of the larvae in the toxicity test above, scanning electron microscopy was used to observe the antenna and sensilla of the fifth instar larvae fed with maize leaves treated with $1 \mathrm{mg} / \mathrm{L}$ of azadirachtin and without azadirachtin after $24 \mathrm{~h}$. Compared with the larvae fed with maize leaves without azadirachtin, the antennae of the larvae fed with maize leaves treated with $1 \mathrm{mg} / \mathrm{L}$ azadirachtin retracted into the antennal nest, indicating that azadirachtin has a certain sensory effect on S. frugiperda (Figure 2). In addition, further observation found that the sensillum basiconicum of the larvae fed with maize leaves treated with $1 \mathrm{mg} / \mathrm{L}$ azadirachtin showed obvious damage, such as fold and fracture (Figure 3). The results indicated that azadirachtin could stimulate the sensory organs of S. frugiperda, which may affect the feeding behavior of S. frugiperda. 


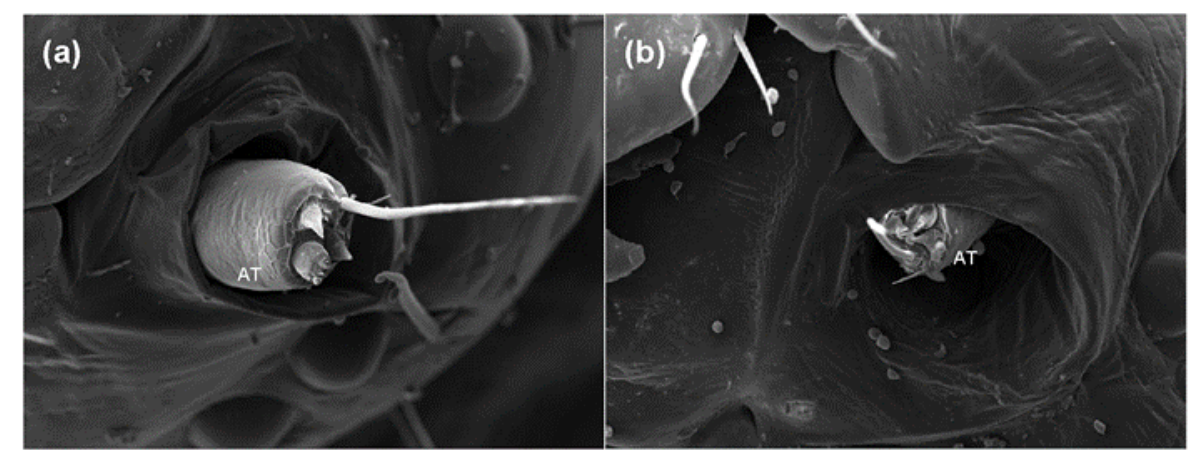

Figure 2. Morphological differences in the antenna of the 5th larvae of $S$. frugiperda after feeding on maize leaves without azadirachtin (a) and treated with $1 \mathrm{mg} / \mathrm{L}$ of azadirachtin (b); AT: Antenna.

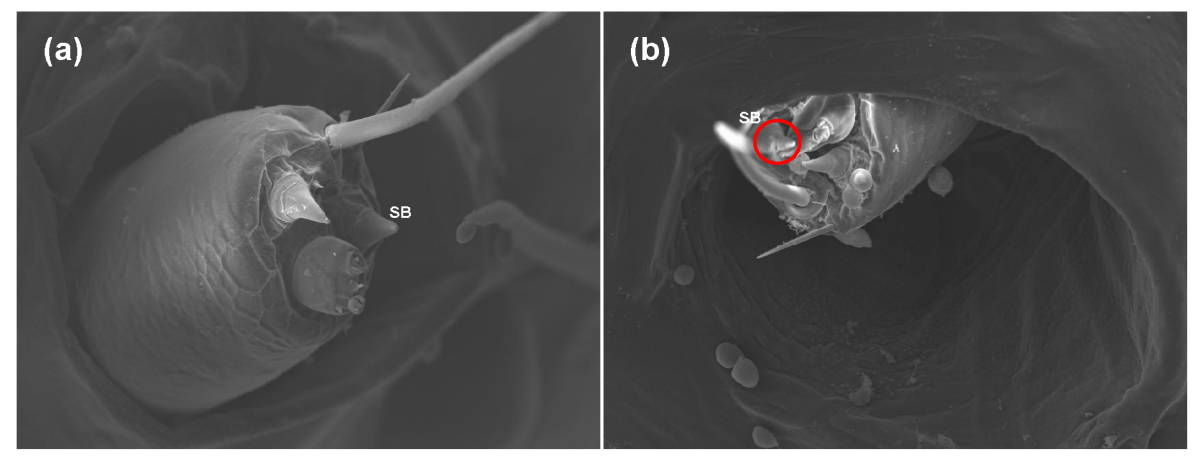

Figure 3. Morphological differences in the sensilla of the 5th larvae of $S$. frugiperda after feeding on maize leaves without azadirachtin (a) and treated with $1 \mathrm{mg} / \mathrm{L}$ of azadirachtin (b); SB: sensillum basiconicum.

\subsection{Effects of Azadirachtin on Sensilla in the Feeding of S. frugiperda}

The micro-drop method was used to further verify the effects of azadirachtin treatment on four sensilla in the feeding of $S$. frugiperda. The cumulative feeding rates of the tested larvae on maize leaves changed into an "S" shape and increased with the increase of time within $48 \mathrm{~h}$ (Figure 4). At the same time point, the cumulative feeding rates decreased with the increase in azadirachtin concentration, and the cumulative feeding rates of the larvae fed with maize leaves containing azadirachtin were significantly lower than those of the larvae fed with maize leaves without azadirachtin, indicating that S. frugiperda had an obvious antifeeding effect after sensillum basiconicum was treated with azadirachtin (Figure $4 a$ ). In Figure $4 b$, the cumulative feeding rates of the larvae feeding on maize leaves containing azadirachtin were significantly lower those that of the larvae feeding on maize leaves without azadirachtin after $16 \mathrm{~h}$, indicating that azadirachtin treatment on sensillum styloconicum can also affect the feeding of $S$. frugiperda. In contrast, there was no significant difference in the cumulative feeding rates of the larvae feeding on maize leaves containing azadirachtin and the larvae feeding on maize leaves without azadirachtin at 8 and $16 \mathrm{~h}$, indicating that there was no significant effect on the feeding of $S$. frugiperda when sensillum trichodeum or sensillum chaeticum was treated with azadirachtin (Figure 4c,d). These results showed that azadirachtin will affect the feeding of $S$. frugiperda after contact with the sensillum trichodeum or sensillum chaeticum. 

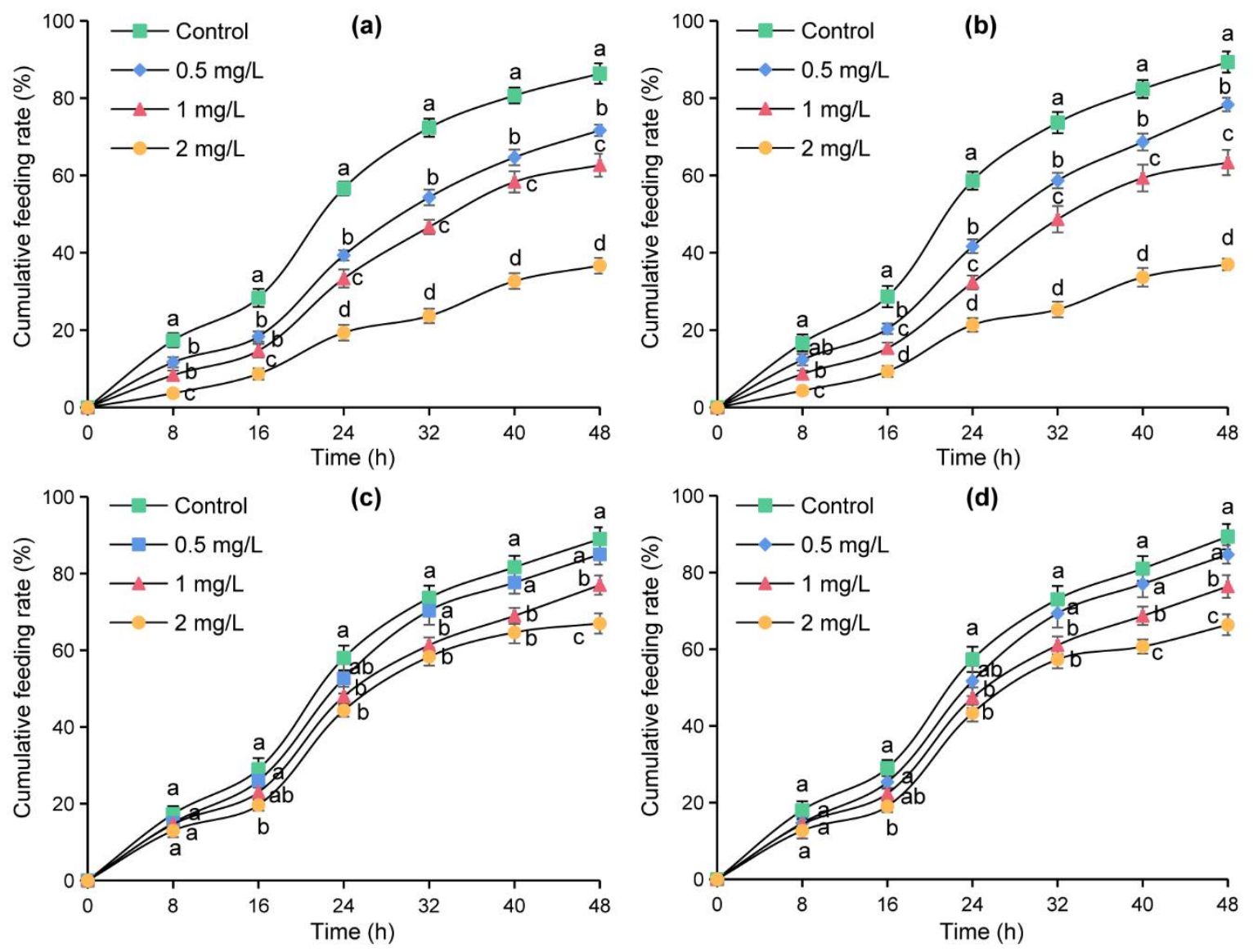

Figure 4. Cumulative feeding rates of $S$. frugiperda after treatment with different concentrations of azadirachtin on sensillum basiconicum (a), sensillum styloconicum (b), sensillum trichodeum (c), and sensillum chaeticum (d), respectively. Data are presented as mean \pm standard error (S.E.). Different letters at each recording time point indicate significant differences among treatments at $p<0.05$ level based on Tukey's HSD test $(n=3)$.

\subsection{Effects of Azadirachtin on Predatory Behavior of S. frugiperda}

In the experiment of the effects of azadirachtin on the predatory behavior of S. frugiperda to $R$. maidis, the leaf consumption rates and number of aphids killed in 1 day of 3 groups are shown in Figure 5. On day 1, the leaf consumption rate of the 'Leaf' group was $5.00 \%$, which was significantly lower than the 'Leaf + Aphid' group of $28.33 \%$, and both groups were significantly lower than the control group of $66.67 \%$, which showed that azadirachtin has an obvious antifeedant activity against $S$. frugiperda. On days 2 and 3 , there was interestingly no significant difference between the leaf consumption rates of the 'Leaf' group and 'Leaf + Aphid' group, but both groups of leaf consumption rates were significantly lower than the control group (Figure 5a). After recording the number of aphids eaten in 1 day, we found that only 4.33 aphids were eaten in the control group on day 1, which was significantly lower than the 'Leaf + Aphid' group of 9.67, and the number of aphids eaten in 'Leaf' group was reached 17.67. On days 2 and 3, there was no significant difference between the number of aphids eaten in the 'Leaf' group and 'Leaf + Aphid' group, but both numbers of aphids eaten in the two groups were significantly higher than the control group (Figure $5 b$ ). 

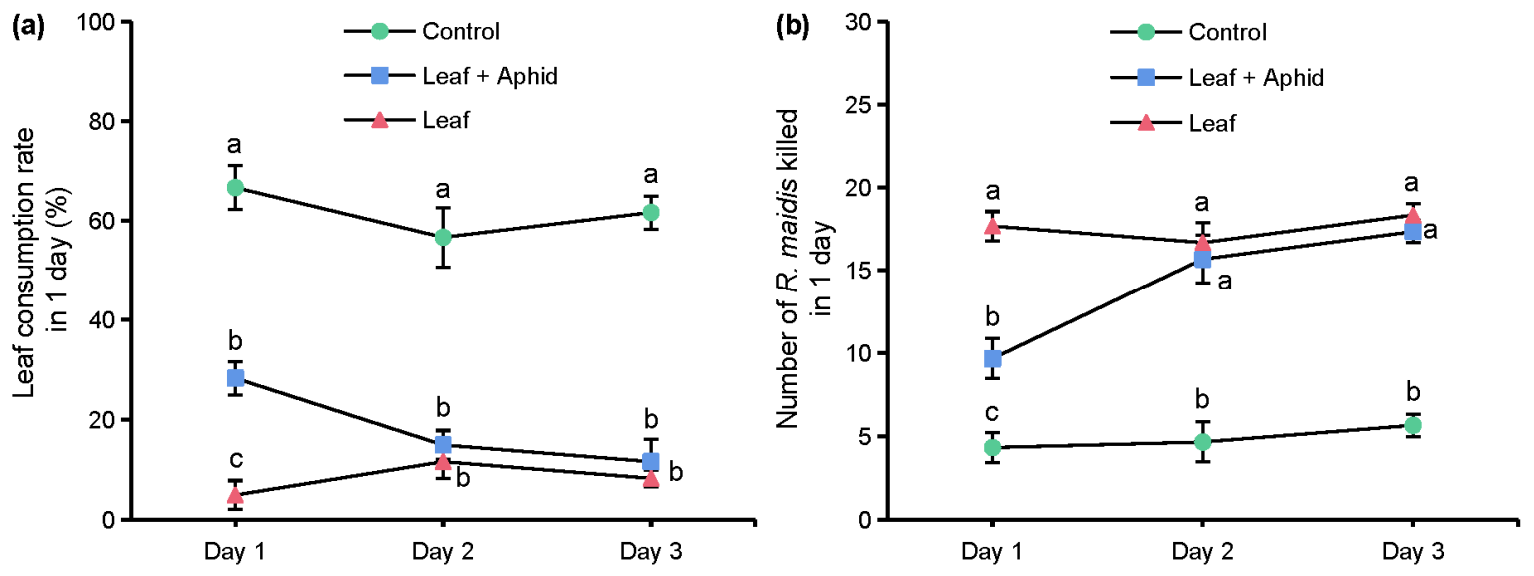

Figure 5. Leaf consumption rate in 1 day (a) and number of $R$. maidis killed in 1 day (b). 'Leaf' indicates leaves soaked with $1 \mathrm{mg} / \mathrm{L}$ of azadirachtin solution and aphids sprayed with $70 \%$ acetone aqueous solution. 'Leaf + Aphid' indicates treating leaves and aphids with $1 \mathrm{mg} / \mathrm{L}$ of azadirachtin solution. 'Control' indicates leaves and aphids treated with $70 \%$ acetone aqueous solution. Data are presented as mean \pm S.E. Different letters at each sampling day indicate significant differences among treatments at $p<0.05$ level based on Tukey's HSD test $(n=3)$.

\subsection{Effects of Aphid Molting on Predatory Behavior of S. frugiperda under Azadirachtin Treatment}

The predation preference rates of $S$. frugiperda to R. maidis before and after aphid molting were tested and compared under $1 \mathrm{mg} / \mathrm{L}$ of azadirachtin treatment. Before aphid molting, the predation preference rates of $S$. frugiperda to aphid and maize leaf were $56.67 \%$ and $43.33 \%$, respectively; however, the predation preference rates of $S$. frugiperda to aphid increased to $91.67 \%$ after aphid molting, and the predation preference rates of $S$. frugiperda to maize leaf decreased to only $9.33 \%$ (Figure 6). The results showed that aphid molting will increase the predation preference rate of $S$. frugiperda to aphids and decrease the predation preference rate of $S$. frugiperda to maize leaf.

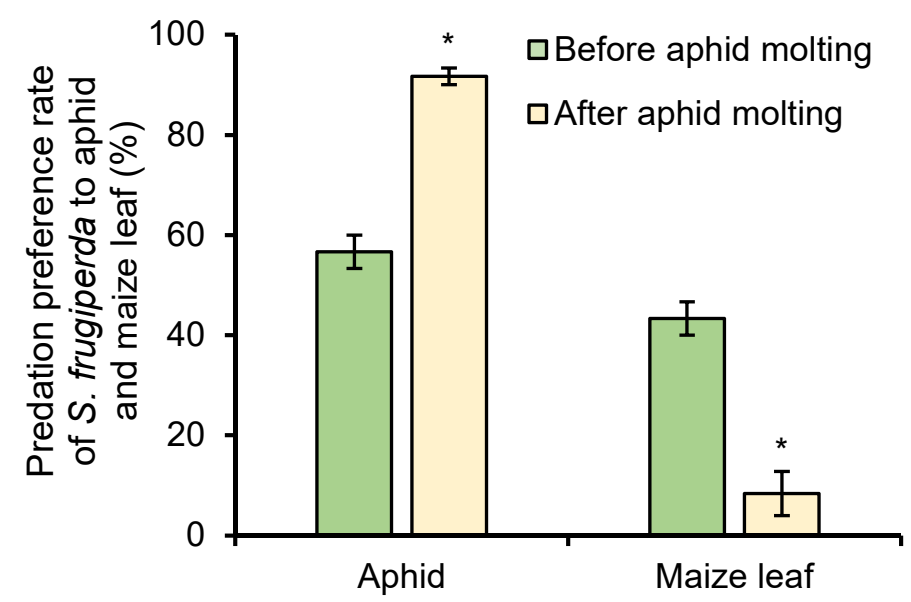

Figure 6. Predation preference rate of $S$. frugiperda to aphid and maize leaf before and after aphid molting under $1 \mathrm{mg} / \mathrm{L}$ of azadirachtin treatment. Data are presented as mean \pm S.E. ${ }^{* \prime \prime}$ represents significant differences between two situations at $p<0.05$ level based on Tukey's HSD test $(n=3)$.

\section{Discussion}

As an omnivorous invasive species, $S$. frugiperda causes serious damage to maize in China [26]. Traditional chemical control is prone to environmental pollution and resistance issues $[27,28]$. Maize producers need more greener, environmentally friendly, simple preventive control technology. Previous studies have shown that azadirachtin has a variety of biological effect on insects, such as anti-feeding, avoidance, cytotoxicity, and so 
on $[29,30]$. Due to its chemical complexity, azadirachtin has many anti-insect properties but no resistance problem [31]. In addition, this compound has also been reported as safer for non-target organisms [32]. In this study, the toxicity of azadirachtin against S. frugiperda was tested. From the experimental results of the toxicity test, little mortality of $S$. frugiperda was observed in the first two days after exposure to azadirachtin treated maize leaves. Additionally, the undead larvae of S. frugiperda appeared to exhibit obvious avoidance and antifeeding toward the maize leaves that contained azadirachtin. Therefore, a sublethal concentration of $1 \mathrm{mg} / \mathrm{L}$ was selected for subsequent experiments to highlight the sublethal effect of azadirachtin.

During the process of insect predation, the antenna and olfactory sensilla have an important role in the identification and positioning of the host plants, and insect sensilla can sensitively sense external signals, which is an important material basis for information exchange between insects and the outside world [33]. Thus, the study of antenna and sensilla can help us to understand the mechanism of the predation behavior of $S$. frugiperda. Different sensilla have different functions; it is generally believed that the sensillum trichodeum is mainly used to perceive and distinguish sex pheromones, and the sensillum chaeticum is mainly used to feel external mechanical stimuli [34]. In addition, the sensillum basiconicum is mainly used to feel the stimulation of plant volatiles, and the sensillum styloconicum mainly has the function of sensing taste stimulation [35]. Azadirachtin has antifeedant effect on S. litura and other lepidopterous larvae [36]. However, the target sensilla of azadirachtin on $S$. frugiperda larvae have not been reported. In view of this, the changes of sensilla and antennae of the fifth instar larvae of $S$. frugiperda fed with maize leaf treated with $1 \mathrm{mg} / \mathrm{L}$ of azadirachtin were observed after $24 \mathrm{~h}$. Results showed that the antennae of $S$. frugiperda contracted into the antennal fossa (Figure 2), and the sensillum basiconicum was broken under azadirachtin treatment (Figure 3). This indicated that azadirachtin has a certain irritant effect on S. frugiperda, and the damage of sensillum basiconicum may affect the feeding behavior of $S$. frugiperda. In the experiment, four main sensilla were subsequently treated with azadirachtin, respectively, to determine the target sensilla and effect of azadirachtin on the feeding of $S$. frugiperda larvae. The results showed that sensillum basiconicum and sensillum styloconicum are the main target sensilla (Figure 4), which play an important role in the feeding process of $S$. frugiperda.

In the experiment of the effects of azadirachtin on the predatory behavior of $S$. frugiperda to $R$. maidis, it can be seen that after maize leaves were treated with $1 \mathrm{mg} / \mathrm{L}$ of azadirachtin, the $S$. frugiperda larvae showed obvious antifeeding phenomena, the leaf consumption rate on day 1 was only $5.00 \%$ compared to the control group of $66.67 \%$ (Figure 5a), and the larvae tended to prey on those foods that did not contain azadirachtin, such as aphids. When both maize leaves and aphids were treated with azadirachtin, the leaf consumption rate on day 1 was $28.33 \%$, and 9.67 aphids were eaten by the larvae (Figure 5b); however, interestingly, the leaf consumption rate and the number of aphids eaten on day 2 changed significantly, the leaf consumption rate was decreased to $15 \%$, and the number of aphids eaten by the larvae increased to 15.67. R. maidis larva has four instar stages and molts every 1 2 days $[37,38]$. Therefore, it is speculated that the molting of aphids may reduce azadirachtin residues and promote this change of predatory behavior. Taking maize leaves treated with azadirachtin as a comparison, the predation preference rates of S. frugiperda to R. maidis before and after aphid molting were measured and compared to determine the effect of aphid molting on the predatory behavior of $S$. frugiperda under azadirachtin treatment. After aphid molting, the predation preference rate of S. frugiperda to R. maidis was increased from $56.67 \%$ to $91.67 \%$ (Figure 6), which indicated that the molting of aphid can inhibit the effect of azadirachtin to the predatory behavior of $S$. frugiperda, which can achieve the purpose of protecting maize and preying on aphids, thereby reducing the application of pesticides.

In this study, azadirachtin could affect the feeding behavior of S. frugiperda, causing it to prey on R. maidis; it may instead be effective in killing R. maidis, significantly reducing the use of pesticides and protecting maize. Additionally, the molting of aphids could promote 
the change in feeding behavior of $S$. frugiperda. Our study, for the first time, demonstrated that this combined control technology of azadirachtin insecticide and biological control could be considered as a new way for green, environmental protection and light control technology, with good ecological, environmental, and economic benefits.

\section{Conclusions}

In this study, we determined the reason for the repellent and antifeedant activity of azadirachtin on $S$. frugiperda and proposed that $S$. frugiperda treated with azadirachtin would turn from pest into natural enemy. Azadirachtin has stimulating and damaging effects on the antennae and sensillum basiconicum of $S$. frugiperda larvae and can affect the feeding behavior of $S$. frugiperda. When maize leaves or maize leaves + aphids are treated with azadirachtin, $S$. frugiperda will feed less on maize leaves and increase their predation preference rate for aphids, and the molting of aphids will promote a change of this feeding behavior. Our study combines azadirachtin insecticide with biological control and suggests that the combined control technology could be a new way for integrated pest management and has good ecological, environmental, and economic benefits. Future studies will focus on how to apply this combined control technology systematically to the field control of S. frugiperda.

\section{Materials and Methods}

\subsection{Plant, Insects, and Chemicals}

The test maize (Corn Four) was planted in Zixi village, Huashan Town, Huadu District, Guangzhou, China $\left(113^{\circ} 26^{\prime} 50.43^{\prime \prime} \mathrm{N}, 2^{\circ} 48^{\prime} 66.63^{\prime \prime} \mathrm{E}\right)$. No pesticides were sprayed before and during the experiment. In the fields, eggs of $S$. frugiperda were collected as the test source. After the eggs were hatched, they were fed with young maize leaves until 5th instar larvae for test. The feeding conditions were under controlled temperature $\left(24 \sim 28^{\circ} \mathrm{C}\right)$, relative humidity (55 65\%), and photoperiod (16:8 L:D). $R$. maidis was also collected from the fields. Subsequently, the aphids were reared on maize leaves in a plastic culture dish (9 $\mathrm{cm}$ in diameter and $1 \mathrm{~cm}$ in height) in a growth chamber and maintained under controlled temperature $\left(24 \sim 28{ }^{\circ} \mathrm{C}\right)$, relative humidity $(55 \sim 65 \%)$, and photoperiod (12:12 L:D). To prevent malnutrition, fresh leaves were provided every $2 \sim 3$ days.

Azadirachtin standard product $(>90 \%)$ was kindly provided by Associate Professor Yongqing Tian of the Key Laboratory of Natural Pesticide and Chemical Biology of the Ministry of Education of South China Agricultural University. Azadirachtin was dissolved in acetone and the solution diluted to $100 \mathrm{mg} / \mathrm{L}$ in water and acetone $(v / v=30: 70)$ and stored at $4{ }^{\circ} \mathrm{C}$ in freezer.

\subsection{Toxicity of Azadirachtin to S. frugiperda}

The objective of this experiment was to determine the sublethal concentration of azadirachtin to $S$. frugiperda for use in subsequent experiments. The azadirachtin standard solution was diluted in $70 \%(v / v)$ acetone aqueous solution to give concentrations of 20,10 , $5,2,1$, and $0.5 \mathrm{mg} / \mathrm{L}$, and $70 \%$ acetone aqueous solution was taken as control. All solutions were freshly prepared. In this experiment, adequate fresh maize leaves were soaked in different concentrations of azadirachtin solution for $3 \mathrm{~s}$ and dried naturally, and then put into a culture dish ( $9 \mathrm{~cm}$ in diameter and $1.5 \mathrm{~cm}$ in height), respectively, for moisturizing every day; finally, a $5^{\text {th }}$ instar larva of $S$. frugiperda was put into each dish. Each treatment tested 20 larvae and was repeated 3 times. Three days after treatment, the survival state of the larvae in each treatment was examined. If the brush touched the surface of larva, no reaction was judged as death. The number of dead larvae was recorded, and the mortality of $S$. frugiperda was calculated based on the equation below:

$$
\text { Mortality rate }(\%)=\left(\mathrm{m}_{1} / \mathrm{m}_{2}\right) \times 100 \%
$$

where $\mathrm{m}_{1}=$ the number of dead larvae, and $\mathrm{m}_{2}=$ the number of total larvae measured. 


\subsection{Effects of Azadirachtin on the Antennae and Sensilla of S. frugiperda}

Based on the results of the above toxicity experiment, $70 \%$ acetone aqueous solution containing $1 \mathrm{mg} / \mathrm{L}$ azadirachtin was selected as sublethal level for the subsequent experiments. It was found that $S$. frugiperda showed obvious avoidance and antifeeding phenomena to the maize leave which contained azadirachtins. In order to explore the reason, the changes of antennae and sensilla of the 5 th instar larvae of $S$. frugiperda treated with azadirachtin were observed by scanning electron microscope. After the 5th instar larvae of $S$. frugiperda were starved for $4 \mathrm{~h}$, larvae in treatment group were reared with maize leaves treated with $1 \mathrm{mg} / \mathrm{L}$ azadirachtin, and larvae in control group were reared with maize leaves without azadirachtin. Each group tested 10 larvae and repeated 3 times. After $24 \mathrm{~h}$ of treatment, the larvae were immersed in phosphate-buffered solution, and their heads were cut off with a razor blade, placed in a centrifuge tube containing $5 \%$ glutaraldehyde, aspirated to precipitate, fixed for $24 \mathrm{~h}$ in $4{ }^{\circ} \mathrm{C}$ freezer, and taken out and washed with $0.1 \mathrm{~mol} / \mathrm{L}$ phosphate buffer ( $\mathrm{pH}=7.2) 3$ times, 20 min each time. Then, 30\%, 50\%, $70 \%, 80 \%, 90 \%$, and $95 \%$ ethanol dehydration was performed, successively, 15 min each time, followed by dehydration with $100 \%$ ethanol 3 times, 20 min each time. The samples were dried at the critical point for $3 \mathrm{~h}$, then stuck on the sample table with conductive glue, sprayed gold, and placed under scanning electron microscope. The accelerating voltage was $20 \mathrm{kV}$. Changes of antennae and sensilla were observed, and pictures were taken.

\subsection{Treatment of Four Sensilla by Azadirachtin Solution}

To further determine the cause of the influence of azadirachtin on the feeding behavior of $S$. frugiperda, the micro-drop method was used to determine the feeding changes of the 5 th instar larvae of $S$. frugiperda after the four sensilla (sensillum basiconicum, sensillum styloconicum, sensillum trichodeum, sensillum chaeticum) were treated with different concentrations $(2,1$, and $0.5 \mathrm{mg} / \mathrm{L})$ of azadirachtin. In this experiment, the larvae were starved for $4 \mathrm{~h}$, and the four sensilla on the head surface of the larva were treated with azadirachtin solution, respectively. Each treatment was dropped with $0.1 \mu \mathrm{L}$, and each group was treated with 20 larvae, repeated 3 times. Afterwards, the larvae were placed in a culture dish with two maize leaves $(5 \mathrm{~cm} \times 5 \mathrm{~cm})$ for feeding observation, respectively. Finally, the maize leaf area was counted at $8,16,24,32,40$, and $48 \mathrm{~h}$, and the cumulative feeding rate of the larvae was calculated based on the equation below:

$$
\text { Cumulative feeding rate }(\%)=\left(\mathrm{n}_{1} / \mathrm{n}_{2}\right) \times 100 \%
$$

where $\mathrm{n}_{1}=$ the maize leaf area eaten by larva, and $\mathrm{n}_{2}=$ total maize leaf area.

\subsection{Effects of Azadirachtin on Predatory Behavior of S. frugiperda}

This experiment was divided into 3 groups to determine the effects of azadirachtin on predatory behavior of $S$. frugiperda. In first group, which is called 'Leaf', fresh maize leaves were cut into $5 \mathrm{~cm} \times 5 \mathrm{~cm}$, soaked in $1 \mathrm{mg} / \mathrm{L}$ azadirachtin solution for $3 \mathrm{~s}$, and dried naturally. Then, a leaf was placed in a culture dish $(9 \mathrm{~cm}$ in diameter and $1.5 \mathrm{~cm}$ in height), 20 young aphids with $70 \%$ acetone aqueous solution sprayed and dried were put into the dish, and finally, a $5^{\text {th }}$ instar larva was introduced. Leaf and aphids were replaced every day. In second group, which was called 'Leaf + Aphid', aphids were sprayed with $1 \mathrm{mg} / \mathrm{L}$ azadirachtin solution, and the other steps were the same as those of first group. In control group, the leaves were soaked in $70 \%$ acetone aqueous solution, the aphids were sprayed with $70 \%$ acetone aqueous solution, and the other steps were the same as those of first group. Each group tested had 20 larvae, and tests were repeated 3 times. The number of aphids eaten every day was recorded. Additionally, the leaf consumption rate was calculated using the equation below:

$$
\text { Leaf consumption rate }(\%)=\left(\mathrm{p}_{1} / \mathrm{p}_{2}\right) \times 100 \%
$$

where $\mathrm{p}_{1}=$ the maize leaf area eaten by larva, and $\mathrm{p}_{2}=$ maize leaf area. 


\subsection{Effects of Aphid Molting on Predatory Behavior of S. frugiperda under Azadirachtin Treatment}

The predation selectivity of $S$. frugiperda to $R$. maidis was tested and compared before and after aphid molting to determine the effects of aphid molting on predatory behavior of S. frugiperda under azadirachtin treatment; maize leaves treated with $1 \mathrm{mg} / \mathrm{L}$ azadirachtin solution were used as a comparison. In this experiment, maize leaf was soaked in $1 \mathrm{mg} / \mathrm{L}$ azadirachtin solution and dried naturally, then placed in a culture dish $(9 \mathrm{~cm}$ in diameter and $1.5 \mathrm{~cm}$ in height). At the same time, 20 aphids sprayed with $1 \mathrm{mg} / \mathrm{L}$ azadirachtin solution then dried were introduced, and finally, a $5^{\text {th }}$ instar larva was introduced after starved for $4 \mathrm{~h}$. Then, we observed whether the larva consumed the leaf or aphid first and recorded the number of larvae which selected an aphid first. In order to test the predation preference rates of $S$. frugiperda to $R$. maidis after aphid molting, 20 aphids sprayed with $1 \mathrm{mg} / \mathrm{L}$ azadirachtin solution and dried were put into a culture dish with azadirachtintreated leaves after molting. Then, a $5^{\text {th }}$ instar larva was introduced after starved for $4 \mathrm{~h}$. Finally, we observed whether the larva consumed the leaf or aphid first and recorded the number of larvae which first selected to eat an aphid. Twenty larvae were tested, and tests were repeated 3 times. The predation preference rates to $R$. maidis were calculated using the equation below, and the predation preference rates before and after aphid molting were compared:

$$
\text { Predation preference rate }(\%)=\left(q_{1} / q_{2}\right) \times 100 \%
$$

where $\mathrm{q}_{1}=$ the number of larvae first selecting to eat aphid, and $\mathrm{q}_{2}=$ the number of total larvae measured.

\subsection{Data Analysis}

Collected data from the aforementioned experiments were subjected to one-way analysis of variance (ANOVA) using SPSS Statistics, Version 17.0, 2009 (International Business Machines Corporation, Armonk, NY, USA). If significant differences occurred among treatments, means were separated by Tukey's honestly significant difference (HSD) test at $p<0.05$ level. Means were presented in graphs with standard error, which were drawn using Microsoft Excel.

Author Contributions: Conceptualization, D.C.; Data curation, S.L. (Shengnan Li); Formal analysis, S.L. (Sukun Lin); Funding acquisition, Z.Z.; Investigation, L.Z.; Methodology, H.W.; Writing—original draft, S.L. (Sukun Lin); Writing - review and editing, Z.L. All authors have read and agreed to the published version of the manuscript.

Funding: This work was supported by the Key-Area Research and Development Program of Guangdong Province (No. 2020B020224002) and Guangdong Provincial Special Fund for Modern Agriculture Industry Technology Innovation Teams (No. 2020KJ122).

Institutional Review Board Statement: Not applicable.

Informed Consent Statement: Not applicable.

Acknowledgments: The authors thank Yongqing Tian for kindly providing the chemicals.

Conflicts of Interest: The authors declare no conflict of interest.

\section{References}

1. Tao, F; Zhang, S.; Zhang, Z.; Rötter, R.P. Temporal and spatial changes of maize yield potentials and yield gaps in the past three decades in China. Agric. Ecosyst. Environ. 2015, 208, 12-20. [CrossRef]

2. He, H.; Hu, Q.; Li, R.; Pan, X.; Huang, B.; He, Q. Regional gap in maize production, climate and resource utilization in China. Field Crop. Res. 2020, 254, 107830. [CrossRef]

3. Meng, Q.; Hou, P.; Wu, L.; Chen, X.; Cui, Z.; Zhang, F. Understanding production potentials and yield gaps in intensive maize production in China. Field Crop. Res. 2013, 143, 91-97. [CrossRef]

4. Lima, A.P.S.; Santana, E.D.R.; Santos, A.C.C.; Silva, J.E.; Ribeiro, G.T.; Pinheiro, A.M.; Santos, T.B.F; Blank, A.F.; Araújo, A.P.A.; Bacci, L. Insecticide activity of botanical compounds against Spodoptera frugiperda and selectivity to the predatory bug Podisus nigrispinus. Crop. Prot. 2020, 136, 105230. [CrossRef] 
5. Luis, A.; Xavier, P. Effect of high temperature on the growth and reproduction of corn aphids (Homoptera: Aphididae) and implications for their population dynamics on the northeastern iberian peninsula. Environ. Entomol. 2001, 30, 1127-1134. [CrossRef]

6. Montezano, D.G.; Specht, A.; Sosa-Gómez, D.R.; Roque-Specht, V.F.; Sousa-Silva, J.C.; de Paula-Moraes, S.V.; Peterson, J.A. Host plants of Spodoptera frugiperda (Lepidoptera: Noctuidae) in the Americas. Afr. Entomol. 2018, 26, 286-300. [CrossRef]

7. Babendreier, D.; Koku, A.L.; Beseh, P.; Osae, M.; Nboyine, J.; Ofori, S.E.K.; Frimpong, J.O.; Attuquaye, C.V.; Kenis, M. The efficacy of alternative, environmentally friendly plant protection measures for control of fall armyworm, spodoptera frugiperda, in maize. Insects 2020, 11, 240. [CrossRef] [PubMed]

8. Boaventura, D.; Bolzan, A.; Padovez, F.E.; Okuma, D.M.; Omoto, C.; Nauen, R. Detection of a ryanodine receptor target-site mutation in diamide insecticide resistant fall armyworm, Spodoptera frugiperda. Pest Manag. Sci. 2020, 76, 47-54. [CrossRef]

9. Cui, L.; Bing, C.; Li, Y.; Wang, J.; Yang, D.; Yan, X.; Guo, Y.; Yuan, H. Research and application of chemical control technology against Spodoptera frugiperda (Lepidoptera:Noctuidae) in foreign countries. Plant Prot. 2019, 45, 7-13. [CrossRef]

10. Early, R.; Gonzalez-Moreno, P.; Murphy, S.T.; Day, R. Forecasting the global extent of invasion of the cereal pest Spodoptera frugiperda, the fall armyworm. Neobiota 2018, 40, 25-50. [CrossRef]

11. Lin, W.; Xu, M.; Quan, Y.; Liao, L.; Gao, L. Potential geographic distribution of Spodoptera frugiperda in China based on MaxEnt model. Plant Quar. 2019, 33, 69-73. [CrossRef]

12. Kansiime, M.K.; Mugambi, I.; Rwomushana, I.; Nunda, W.; Day, R. Farmer perception of fall armyworm (Spodoptera frugiderda J.E. Smith) and farm-level management practices in Zambia. Pest Manag. Sci. 2019, 75, 2840-2850. [CrossRef]

13. Tambo, J.A.; Day, R.K.; Lamontagne-Godwin, J.; Silvestri, S.; Beseh, P.K.; Oppong-Mensah, B.; Phiri, N.A.; Matimelo, M. Tackling fall armyworm (Spodoptera frugiperda) outbreak in Africa: An analysis of farmers' control actions. Int. J. Pest Manag. 2020, 6, 298-310. [CrossRef]

14. Zhu, Y.; Blanco, C.A.; Portilla, M.; Adamczyk, J.; Luttrell, R.; Huang, F. Evidence of multiple/cross resistance to Bt and organophosphate insecticides in Puerto Rico population of the fall armyworm, Spodoptera frugiperda. Pestic. Biochem. Physiol. 2015, 122, 15-21. [CrossRef] [PubMed]

15. Robert, L.M.J.; Gregg, S.N.; Rodney, N.N.; Mirian, M.H. Parasitoids attacking fall armyworm (Lepidoptera: Noctuidae) in sweet corn habitats. Biol. Control 2016, 95, 66-72. [CrossRef]

16. Tang, Y.; Wang, M.; Chen, H.; Wang, Y.; Zhang, H.; Chen, F.; Zhao, X.; Zhang, L. Predatory capacity and behavior of Picromerus lewisi Scott against Spodoptera frugiperda higher instar larve. Chin. J. Biol. Control 2019, 35, 698-703. [CrossRef]

17. Kuo, M.H.; Chiu, M.C.; Perng, J.J. Temperature effects on life history traits of the corn leaf aphid, Rhopalosiphum maidis (Homoptera: Aphididae) on corn in Taiwan. Appl. Entomol. Zool. 2006, 41, 171-177. [CrossRef]

18. Foott, W.H. Biology of the corn leaf aphid, Rhopalosiphum Maidis (Homoptera: Aphididae), in Southwestern Ontario. Can. Entomol. 1977, 109, 1129-1135. [CrossRef]

19. So, Y.S.; Ji, H.C.; Brewbaker, J.L. Resistance to corn leaf aphid (Rhopalosiphum maidis Fitch) in tropical corn (Zea mays L.). Euphytica 2010, 172, 373-381. [CrossRef]

20. Shi, Z. Key points of integrated pest control in Maize. Rural Sci. Technol. 2019, 103-104. [CrossRef]

21. Desneux, N.; Decourtye, A.; Delpuech, J.M. The sublethal effects of pesticides on beneficial arthropods. Annu. Rev. Entomol. 2007, 52, 81-106. [CrossRef]

22. Tomé, H.V.V.; Martins, J.C.; Corrêa, A.S.; Galdino, T.V.S.; Pican, O.M.C.; Guedes, R.N.C. Azadirachtin avoidance by larvae and adult females of the tomato leafminer Tuta absoluta. Crop Prot. 2013, 46, 63-69. [CrossRef]

23. Liu, T.; Liu, S.S. Experience-altered oviposition responses to a neem-based product, Neemix, by the diamondback moth, Plutella xylostella. Pest Manag. Sci. 2010, 62, 38-45. [CrossRef] [PubMed]

24. Marrone, P.G. Pesticidal natural products-status and future potential. Pest Manag. Sci. 2019, 75, 2325-2340. [CrossRef] [PubMed]

25. Lima, D.B.; Melo, J.W.S.; Guedes, N.M.P.; Gontijo, L.M.; Guedes, R.N.C.; Gondim, M.G.C.; Giancarlo, L.M. Bioinsecticide-Predator interactions: Azadirachtin behavioral and reproductive impairment of the coconut mite predator neoseiulus baraki. PLoS ONE 2015, 10, e118343. [CrossRef] [PubMed]

26. Jing, D.P.; Guo, J.F.; Jiang, Y.Y.; Zhao, J.Z.; Sethi, A.; He, K.L.; Wang, Z.Y. Initial detections and spread of invasive Spodoptera frugiperda in China and comparisons with other noctuid larvae in cornfields using molecular techniques. Insect Sci. 2020, 27, 780-790. [CrossRef]

27. Boaventura, D.; Ulrich, J.; Lueke, B.; Bolzan, A.; Okuma, D.; Gutbrod, O.; Geibel, S.; Zeng, Q.; Dourado, P.M.; Martinelli, S.; et al. Molecular characterization of Cry1F resistance in fall armyworm, Spodoptera frugiperda from Brazil. Insect Biochem. Mol. 2020, 116, 103280. [CrossRef]

28. Huang, F.N.; Qureshi, J.A.; Meagher, R.L.; Reisig, D.D.; Head, G.P.; Andow, D.A.; Ni, X.Z.; Kerns, D.; Buntin, G.D.; Niu, Y.; et al. Cry1F resistance in fall armyworm Spodoptera frugiperda: Single gene versus pyramided Bt maize. PLoS ONE 2014, 9, e112958. [CrossRef]

29. Bezzar-Bendjazia, R.; Kilani-Morakchi, S.; Maroua, F.; Aribi, N. Azadirachtin induced larval avoidance and antifeeding by disruption of food intake and digestive enzymes in Drosophila melanogaster (Diptera: Drosophilidae). Pestic. Biochem. Physiol. 2017, 143, 135-140. [CrossRef]

30. Radhika, S.; Sahayaraj, K.; Senthil-Nathan, S.; Hunter, W.B. Individual and synergist activities of monocrotophos with neem based pesticide, Vijayneem against Spodoptera litura Fab. Physiol. Mol. Plant Pathol. 2017, 101, 54-68. [CrossRef] 
31. Mordue, A.J.; Morgan, E.D.; Nisbet, A.J. Azadirachtin, a natural product in insect control. Compr. Mol. Insect Sci. 2005, 6, 117-135. [CrossRef]

32. Barbosa, W.F.; Meyer, L.D.; Guedes, R.N.C.; Smagghe, G. Lethal and sublethal effects of azadirachtin on the bumblebee Bombus terrestris (Hymenoptera: Apidae). Ecotoxicology 2015, 24, 130-142. [CrossRef] [PubMed]

33. Na, M.; Liu, M.T.; Nguyen, M.Q.; Ryan, K. Single-Neuron comparison of the olfactory receptor response to deuterated and nondeuterated odorants. ACS Chem. Neurosci. 2019, 10, 552-562. [CrossRef] [PubMed]

34. Bleeker, M.A.K.; Smid, H.M.; Van Aelst, A.C.; Van Loon, J.J.A.; Vet, L.E.M. Antennal sensilla of two parasitoid wasps: A comparative scanning electron microscopy study. Microsc. Res. Tech. 2004, 63, 266-273. [CrossRef] [PubMed]

35. Loon, V.J.J.A. Chemosensory basis of feeding and oviposition behaviour in herbivorous insects: A glance at the periphery. Entomol. Exp. Appl. 1996, 80, 7-13. [CrossRef]

36. Qin, D.; Zhang, P.; Zhou, Y.; Liu, B.; Zhang, Z. Antifeeding effects of azadirachtin on the fifth instar Spodoptera litura larvae and the analysis of azadirachtin on target sensilla around mouthparts. Arch. Insect Biochem. 2020, 103, 5318. [CrossRef]

37. Mutuel, D.; Ravallec, M.; Chabi, B.; Multeau, C.; Salmon, J.M.; Fournier, P.; Ogliastro, M. Pathogenesis of Junonia coenia densovirus in Spodoptera frugiperda: A route of infection that leads to hypoxia. Virology 2010, 403, 137-144. [CrossRef] [PubMed]

38. Elliott, N.C.; Kieckhefer, R.W.; Walgenbach, D.D. Effects of constant and fluctuating temperatures on developmental rates and demographic statistics for the corn leaf aphid (Homoptera: Aphididae). J. Econ. Entomol. 1988, 81, 1383-1389. [CrossRef] 